\title{
Coréia do Sul e Taiwan enfrentam o desafio da industrialização tardia
}

\section{AMAURT PORTO DE OLIVEIRA}

$\mathrm{N}$ o último quartel do século XVIII, a Inglaterra adquiriu as características de uma economia industrializada, dando início à Idade Industrial. Mas foi somente depois de 1815 , com a sua vitória final nas Guerras Napoleônicas, que o modelo industrial inglês começou a difundir-se pelo mundo, sob a proteçáo da Pax Britannica. As décadas anteriores haviam sido tão conturbadas, que David S. Landes somente encontrou, para defini-las, a metáfora biológica de climatério. Outra dessas fases críticas na evoluçáo da economia mundial sobreveio nos últimos anos do século XIX, estendendo-se até 1945, quando a vitória final dos EUA sobre a Alemanha permitiu a instalaçáo da Pax Americana e a difusão, à sua sombra, de novo modelo industrial, desta vez elaborado nos EUA.

Salta aos olhos de todos que o mundo está atravessando uma terceira fase crítica, a encerrar-se previsivelmente dentro de mais algum tempo com a afirmaçáo de outro modelo industrial, idealmente sem guerra.

A visão dessa recorrência de fases críticas emoldurando a marcha da sociedade industrial parece de grande importância para países quc, como o Brasil, ainda não lograram instalar-se plenamente na modernidade. Os dois séculos já decorridos da Idade Industrial mostram, com efeito, ser nas fases de ruptura das estabilidades hegemônicas que sociedades alertas conseguem realizar a façanha da sua própria industrializaçáo: levar a bom termo o processo para o qual já se consagrou a designaçáo de industrialização tardia. Alemanha e Japão fizeram isso, na passagem do século XIX para o século XX. Coréia do Sul e Taiwan estão igualmente empenhados em tal procedimento neste final de século.

A linha diretora de uma industrialização tardia é a busca coerente e determinada do emparelhamento (catching-up) tecnológico com as economias mais avançadas do período. Taiwan e Coréia do Sul vêm perseguindo esse objetivo cumprindo trajetórias muito parecidas, de etapas definidas por agentes externos: algumas décadas sob colonizaçăo 
japonesa antes da Segunda Guerra Mundial; libertaçáo e inserção na economia internacional sob a égide da hegemonia americana; retorno à zona de influência do Japáo, transformado em locomotiva da passagem a um novo sistema técnico.

Apesar dessas similitudes, Taiwan e Coréia do Sul văo se modernizando cada um à sua maneira, levados por suas histórias concretas a adotar, respectivamente, a via chinesa e a via japonesa de modernização. Independentemente da via tomada, Taiwan e Coréia do Sul cuidaram desde o início de expor seus produtos à concorrência internacional, como a melhor maneira de forçar os produtores locais ao contínuo enobrecimento (up-grading) tecnológico das respectivas exportaçóes. Cuidaram, igualmente, de não se imobilizar no aproveitamento de vantagens comparativas dadas, buscando sempre aumentar os ingressos provenientes das exportaçóes para, com eles, financiar tanto a compra - no exterior - de equipamentos e bens intermediários destinados ao aprofundamento da política de substituição de importações; quanto a ampliaçáo dos reduzidos mercados internos.

Por princípio, Coréia do Sul e Taiwan somente se voltaram à exportaçáo de bens de capital após a consolidaçáo do correspondente mercado doméstico. Para isso, o governo desses países mantinha-se atento ao controle - por nacionais - das produçóes selecionadas como de valor industrializante, assim também como à adequada redistribuição social dos ganhos de exportação.

Em Taiwan, a partir de 1949, e na Coréia do Sul com a instalaçáo do regime Park Chung-hee (1961-1979), firmaram-se versóes locais do Estado desenvolvimentista de tipo japonês. Um Estado dedicado à edificaçáo em contexto capitalístico, vale dizer, atuando para o mercado e através do mercado, de sociedades modernas habilitadas a conquistar lugar próprio no mundo da segunda metade do século XX. Somente o que fosse conducente a esse ideal era deixado medrar.

Chalmers Johnson, um dos melhores especialistas americanos nas economias do Leste asiático, sintetizou em quatro pontos o modelo estrutural que tem presidido ao extraordinário êxito econômico dos NPIs (novos paises industriais) daquela região:

- estabilidade governamental assegurada por elite político-administrativa, infensa a reivindicaçóes políticas suscetíveis de solapar o crescimento econômico;

- cooperaçáo entre os setores público e privado, sob a orientação geral de organismo governamental de planejamento; 
- investimentos contínuos e maciços no sistema de educaçáo universal, em combinaçáo com políticas que assegurem a distribuição eqüitativa da riqueza criada pelo crescimento acelerado;

- governo que compreenda a necessidade de usar e respeitar métodos de intervençáo econômica, baseados no mecanismo dos preços (cf. o importante artigo de Johnson, na coletânea compilada por Scalapino, Robert A. et al., Asian economic development - present and future, Berkeley, University of California, 1985).

Graças ao exposto, Taiwan e Coréia do Sul chegaram ao final dos anos 70 semipreparados para os desafios da nova época em vias de abrir-se. A capacidade industrial de ambos os países aumentara significativamente, seus ritmos de crescimento econômico alcançavam índices excepcionais e suas exportaçōes derramavam-se pelo mundo. Mas a base tecnológica sobre a qual se apoiava esse progresso continuava deficiente e desequilibrada, e muito dependia ainda do acesso favorecido ao mercado importador dos EUA.

No Brasil ainda é usual falar da Coréia do Sul e de Taiwan como simples economias exportadoras. Daí inclusive a persistência em chamá-los tigres, em alusão à agressividade com que, nos anos 60 , souberam os dois países asiáticos inserir-se no mercado internacional. Náo havia dúvida que usaram com mestria o fomento das exportaçōes, a fim de gerar os fundos necessários à criaçáo de economias integradas e dinâmicas, esteadas na expansão da demanda interna e na substituiçáo, cada vez mais complexa, das importaçóes. Mas o que importa acentuar é a guinada que Coréia do Sul e Taiwan efetuaram na abertura dos anos 80 , no sentido de uma economia com crescente conteúdo autônomo de ciência e tecnologia. Na América Latina, mesmo Brasil e México não souberam ou não puderam efetuar essa guinada, enleando-se nos bloqueios característicos da década perdida.

Essa divergência básica na maneira como os dois principais NPIs do Leste asiático e os dois principais da América Latina responderam aos desafios dos anos $\mathbf{8 0}$ tem sido muito obscurecida, nem sempre inocentemente, pelo falso dilema entre economias voltadas para dentro e economias abertas ao exterior, esta última fórmula apresentada como a chave da modernidade. A reconstituiçáo da evoluçáo concreta dos dois países asiáticos, em comparaçáo com a dos dois países latino-americanos, traz à luz no entanto situaçóes bem mais complexas do que as agitadas nas simplificaçóes de uso.

Os quatro países em causa buscaram inserir-se na economia internacional liberal criada pela Pax Americana, apoiando-se na exploraçáo 
da vantagem comparativa do baixo custo de suas máos-de-obra. Coréia do Sul e Taiwan liberaram-se crescentemente da situaçáo de produtores de custos baixos, à medida que o progresso econômico fazia crescer os salários reais e os gastos sociais do Estado. $O$ problema que se tem colocado permanentemente para os dois NPIs asiáticos é o de manterem-se competitivos, aumentando o conteúdo tecnológico das suas produçōes.

A História nos ensina que não há automatismo na industrialização das sociedades humanas. Vale dizer, não existe destino manifesto ou lei da evolução econômica que impulsione os países no sentido da industrializaçáo. Chegar lá é, antes de mais nada, a decisão consensual de determinados segmentos do corpo nacional, de cuja ocorrência ao Leste asiático deu conta Chalmers Johnson, consoante a citaçáo que dele fizemos anteriormente.

A variável decisiva nas bem-sucedidas industrializaçóes tardias de que há registro tem sido, então, a proficiência com que o Estado desenvolvimentista implemente suas estratégias modernizadoras, em harmonia com a opção industrializante da elite políticó-empresarial. $\mathrm{Na}$ segunda metade do século XX - após a universalizaçáo do modelo americano da II Revoluçáo Industrial e a sujeiçăo da fronteira tecnológica ao capital transnacional - tornou-se também necessário que o Estado desenvolvimentista e os segmentos do empresariado empenhados na industrializaçáo soubessem trabalhar coordenadamente, no seio da chamada triplice alianfa, com as firmas multinacionais. A medida em que exista coordenaçáo entre os componentes nacionais do tripé, tenderá a ser positiva para o objetivo final a contribuiçăo do elemento estrangeiro.

Na segunda metade dos anos $\mathbf{7 0}$ andavam no ar idéias sugerindo o fim da II Revoluçáo Industrial. A partir dali, país que desejasse continuar na rota da modernizaçăo precisava cortar, o mais rápido possível, seus vínculos com o modelo americano daquele período histórico - o fordismo. Imprescindível tornara-se o engajamento com as tecnologias que prenunciavam um novo paradigma sócio-tecnológico.

Em 1979, a Conferência das Naçóes Unidas sobre Ciência e Tecnologia para o Desenvolvimento, reunida em Viena, tornou claro também que os países do Sul desejosos de modernizar-se precisavam dotar-se da capacidade de absorver tecnologia. Sem a capacidade para selecionar - no acervo mundial - as tecnologias que realmente thes possam ser úteis; sem o preparo para modificar as tecnologias escolhidas, de maneira a adequá-las às condiçóes e recursos presentes no 
âmbito nacional; e sem a aptidão para gerar, ou assimilar, internamente os conhecimentos imprescindíveis para o bom aproveitamento das tecnologias já adequadas, dificilmente poderá um país conquistar, hoje, a verdadeira modernização.

O segredo do êxito continuado dos NPIs asiáticos está claramente ligado à maneira como suas coalizóes industrializantes, guiadas com mão segura pelo Estado desenvolvimentista, vêm respondendo aos desafios acima resumidos. Eles deslocaram suas preocupaçóes, da edificaçáo de uma pesada economia fordista buscada nos anos 70, para a criação de um sistema dinâmico e flexível de atividades com maior conteúdo científico e tecnológico. É sugestivo verificar como Taiwan e Coréia do Sul efetuaram a correspondente guinada quase simultaneamente.

Em Taiwan, promovida pelo recém-criado Conselho Nacional de Ciência, reuniu-se em 1978 a Primeira Conferência Nacional de Ciência e Desenvolvimento. O objetivo era elaborar um programa de longo alcance para situar a economia taiwanesa na perspectiva do século XXI e, para tanto, a conferência adotou um programa apoiado em quatro linhas-de-forças:

- desenvolvimento e treinamento da força-de-trabalho nos diferentes níveis de ensino;

- desenvolvimento intensivo da C\&T em oito áreas consideradas cruciais para o progresso do país;

- aperfeiçoamento do ambiente interno para as atividades de C\&T, através de legislaçáo de incentivo e apoio a empresas de risco nas oito áreas-chaves, e a criaçáo de um parque industrial reservado a indústrias de alto conteúdo científico;

- estímulo à cooperação interindustrial voltada para a formação de recursos humanos, financeiros e de mercado, necessários ao desenvolvimento das tecnologias modernas.

O governo da Coréia do Sul procedeu, em dezembro de 1980, a uma série de fusões de instituições científicas, reduzindo o número delas de 19 para 13, com o objetivo de criar massa crítica para a promoçáo das atividades da C\&T , dando melhor aproveitamento aos recurso de que dispunha o país. Alguns meses depois lançou o quinto Plano Qüinqüenal de Desenvolvimento Econômico e Social (1982-86), com forte orientaçáo para as atividades de C\&T. Nessa linha foi criado em 1984 o 
Conselho de Ciência e Tecnologia, órgão superior de coordenaçáo e monitoramento das diferentes repartiçóes na área de C\&T.

No centro dessas reorganizaçóes institucionais ganhava força a preocupaçáo das coalizóes industrializantes, nos dois países em causa, com o problema da equiparação tecnológica. Ao tomarem consciência da exaustão do valor estruturante do fordismo, as elites governamental e empresarial de Coréia do Sul e Taiwan davam-se conta de que as características dessa equiparação haviam mudado. Adquiriam maior importância o que alguns economistas começam a estudar sob o nome de fontes intangtveis de crescimento.

A essência do fordismo consistiu, notoriamente, na produção em massa de produtos estandardizados por meio de máquinas dedicadas, e com o trabalho parcelizado ao longo de linhas de produçáo que se movem em cadência rígida. Essa organizaçáo da produção favorecia economias de escala, técnicas intensivas em capital e competiçáo baseada no preço do produto final, a qual por sua vez levava à busca permanente de reduçáo dos custos, com efeitos sobre o nível dos salários. No paradigma em eclosão, o trabalho industrial organiza-se seguindo rede de minilinhas, entre as quais o produto circula em cadências flexíveis e trajetórias complexas, sob a atenção de núcleos de trabalhadores intelectualmente despertados para o processo.

Nesse novo sistema, dito de especializagato flextoel, renovam-se as formas de organizaçáo da produçáo e de relacionamento entre as firmas, e entre patróes e operários. O funcionamento do sistema apóia-se em contínua inovaçáo do produto e do processo produtivo; alta qualidade do produto e rapidez da sua entrega; economias de oportunidade, aglomeraçáo e colaboraçáo. $O$ preço torna-se relativamente menos importante e a localização da produção deixa de ser determinada pelos velhos fatores de transporte e custos para ceder à influência das relaçóes de cooperação entre vendedores e clientes, e à qualidade da força-de-trabalho. Taiwan (e Cingapura), economia(s) mais entrosada(s) com o mercado internacional do que a Coréia do Sul, fornece(m) exemplo expressivo da criaçáo local de uma cultura voltada para o preço da produçáo com maior valor agregado. A elevação regular do salário real e do nível de vida da populaçáo está, nesse(s) país(es), muito presa à promoção, sob os cuidados do Estado desenvolvimentista, das vantagens intangiveis.

Mas todo o Leste asiático, do Japão à Malásia, vem sendo desde os anos 80 um grande laboratório onde interagem fatores tangiveis e intangíveis de crescimento, sendo essa uma das principais razóes que 
tornam o estudo da área da maior importância para outros candidatos à industrializaçáo tardia. Nesse contexto, Taiwan e Coréia do Sul distinguem-se, não tanto pela perspicácia das políticas recentes, muito menos pelo passe de mágica da abertura ao exterior, e sim graças ao acúmulo, desde os anos 50, de políticas corretas e carregadas de futuro: a reforma agrária; as políticas educacionais que dotaram os dois países de forçade-trabalho com alto nível de escolaridade e elevado grau de motivação nacionalista, estáo agora preparando a massa da populaçáo para a Idade da Informaçáo; a proteção e incentivo do capital nacional com a contrapartida de lhe cobrarem resultados; a preocupaçáo permanente com a aquisição e assimilação de tecnologia; a extrema habilidade com que os respectivos Estados desenvolvimentistas, fiéis ao princípio magno de o Estado desse tipo trabalhar para o mercado e através do mercado, ter sabido explorar, em benefício da competitividade internacional da produção local, os aspectos políticos dinâmicos do ciclo do produto.

$\mathrm{Na}$ Coréia do Sul e em Taiwan, desde os anos 70 tinham os governantes adquirido a conviç̧áo de que era imprescindível dotar a economia nacional de uma indústria integrada de semicondutores, se se queria levar adiante o processo de industrializaçăo. Inspirando-se no exemplo japonês, os planejadores dos dois NPIs focalizaram o assenhoreamento das técnicas de produção das micropastilhas de memórias como a porta de entrada para os semicondutores e, mais além, o conjunto das tecnologias da informação (TI). Foi-lhes possível começar a caminhar em direção à nova meta, graças ao nível educacional já satisfatório da força-de-trabalho e à experiência adquirida a partir dos anos 60 , através das implantaçóes estrangeiras na eletrônica em geral que vinham sendo toleradas sob vigilância do Estado.

Não disporemos de espaço para contar com minúcias como foram criadas as duas já estabelecidas indústrias de semicondutores. Evocaremos os passos principais.

Em Taiwan, funcionava desde 1973 a estatal Electronics Research and Service Organization (ERSO), com a responsabilidade de buscar parceiros estrangeiros que ajudassem a desenvolver e comercializar a produçáo taiwanesa de semicondutores. Em 1977, a ERSO assinou o desejado contrato com a americana RCA, vindo o governo a investir mais de 3 milhōes de dólares na aquisiçăo de conhecimentos teóricos e formação de especialistas, sob a orientaçáo do sócio. Quando pareceu já existir no país a massa crítica necessária, foram criadas - via ERSO a Unite Microelectronics Corp. (UMC) e a Taiwan Semiconductor Manufacturing Co. (TSMC), segundo o esquema da tríplice aliança, mas com o governo taiwanês detendo posiçáo majoritária. 
$\mathrm{Na}$ Coréia do Sul, após anos dc familiarizaçáo com os semicondutores, monitorando o trabalho das implantaçóes estrangeiras, os planejadores governamentais lançaram-se à criação da infra-estrutura de P\&D necessária para a capacitaçáo nacional. Em 1974, o Plano de Oito Anos para o Desenvolvimento da Indústria Eletrônica estabeleceu três metas:

- criar instituiçóes de pesquisa, públicas e privadas, com missóes específicas dentro do propósito geral de levantar a indústria eletrônica;

- expandir a capacidade doméstica de treinamento avançado em eletrônica;

- encorajar as importaçóes de tecnologia por meio de licenciamento e consultoria, evitando os investimentos diretos estrangeiros.

$\mathrm{Na}$ vanguarda dessas três linhas de ação situou-se o Korean Institute of Electronic Technology (KIET), de 1976.

Até a segunda metade dos anos 70, a maior parte da indústria sul-coreana dos semicondutores era de firmas pequenas ocupadas com montagem, encapsulamento e testes de componentes. Alguns chaebols vinham ansiando por entrar no segmento dos semicondutores avançados, mas não viam como ultrapassar as colossais barreiras à entrada no setor. Em 1981 o governo lançou o Plano Básico de Promoçáo da Indústria Eletrônica, e esforço coordenado da coalizáo industrializante nacional foi posto em marcha, usando como alavanca o estreito controle governamental sobre o setor das telecomunicaçóes, ao término do qual companhias como a ITT, AT\&T e Northern Telecom viram-se compelidas a passar aos chaebols sul-coreanos tecnologia quase no estado-daarte para a produção de semicondutores.

Rompidas, assim, as barreiras à entrada na indústria mundial dos semicondutores, foram as atividades correspondentes declaradas de valor estratégico na Coréia do Sul. Instituiu-se a reserva de mercado de várias áreas do setor, e três dos chaebols - Samsung, Goldstar e Hyundai foram estimulados a tomar posiçóes na produçáo das micropastilhas de memórias (d-RAMs), escolhidas para locomotivas tecnológicas dos semicondutores sul-coreanos. Entre 1983-1985 os três chaebols citados investiram, em conjunto, entre 1 e 2 bilhóes de dólares para dar cumprimento à tarefa recebida.

Quando os sul-coreanos dispuseram afinal de produtos (as memórias 64K d-RAM) para oferecer ao mercado internacional, essas mi- 
cropastilhas atravessavam uma de suas retraçóes cíclicas, e os chaebols correram o risco de ver seus investimentos reduzidos a nada. Com o apoio do governo, e graças ao colossal poder de resistência financeira dos conglomerados sul-coreanos, a crise foi superada, e a Coréia do Sul pôde firmar-se como o terceiro produtor mundial de semicondutores. Bem atrás de EUA e Japão, mas solidamente à frente de qualquer país da Europa Ocidental. O Samsung figura hoje entre as quatro ou cinco maiores firmas da indústria mundial, e no tocante às memórias equiparou-se desde 1990 às líderes japonesas do setor.

Em Taiwan, na falta dos poderosos instrumentos que são os chaebols, teve o Estado de continuar quase sozinho a promoçăo da indústria dos semicondutores. Sua principal base de trabalho foi o Parque de Ciência de Hsinchu. Os parques de ciência generalizaram-se nos anos

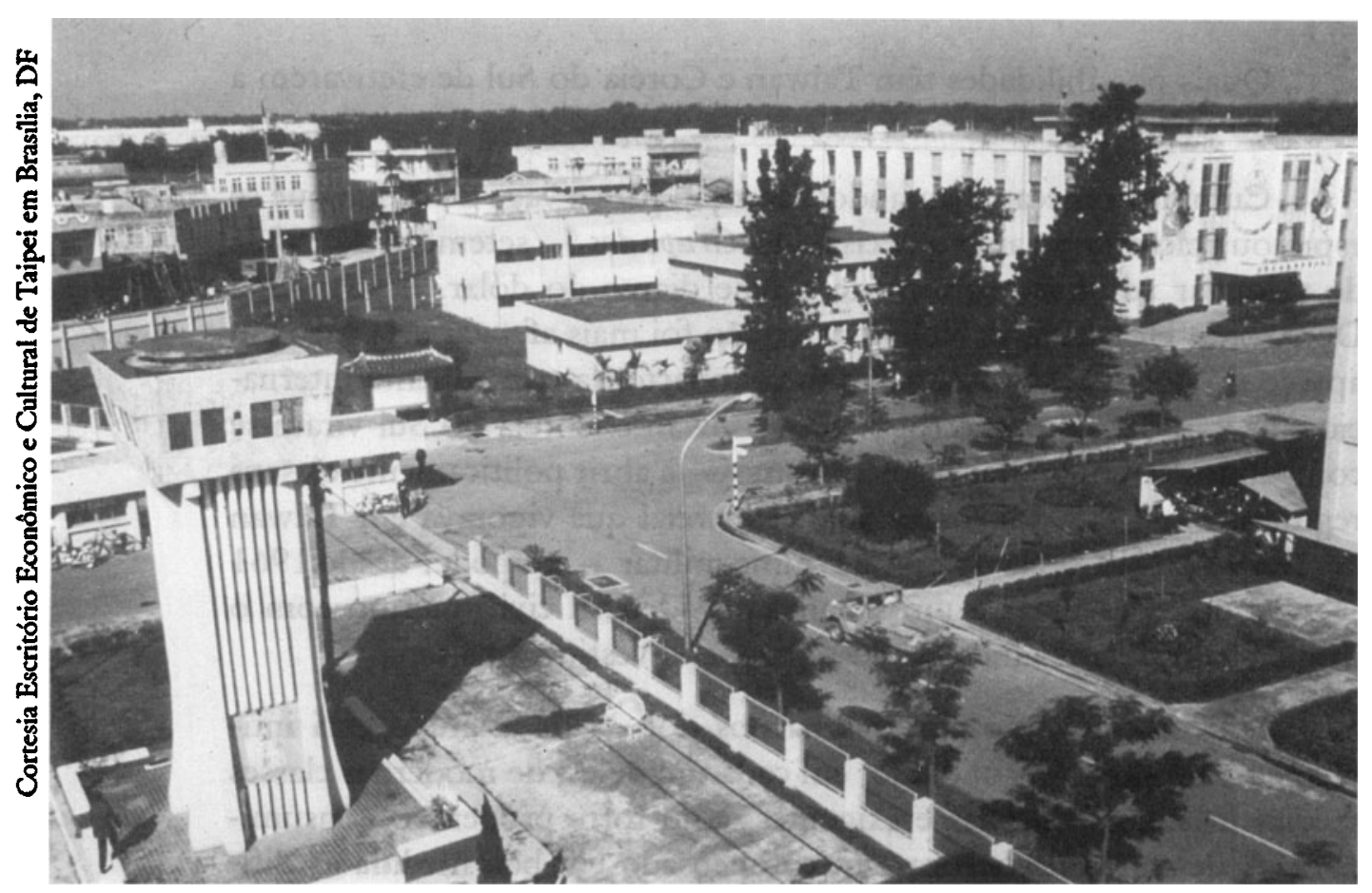

O Parque de Ciência de Hsin-Chu em Taiwan

80 nos países industrializados (EUA e Inglaterra em particular), num quadro conceitual de criaçáo de competitividade comercial para as indústrias de ponta. $O$ Estado desenvolvimentista taiwanês tem usado o conceito, no entanto, para a criação do espaço ideal em que se desenrole, sob seu controle, o jogo de forças da tríplice alianfa, indispensável às industrializaçóes tardias da segunda metade do século XX. Notáveis 
avanços vão sendo obtidos, dessa forma, para a instalaçăo de Taiwan na vaga da III Revoluçáo Industrial, tanto no setor dos semicondutores como, por exemplo, no das biotecnologias.

Coréia do Sul e Taiwan estáo entrando nos anos 90 como economias dinâmicas, às portas da efetiva industrializaçáo. Os avanços dos dois países são irretorquíveis. A indústria sul-coreana dos semicondutores é, certamente, o exemplo mais bem-sucedido de tentativa de país do Sul de lançar âncora no patamar dos industrializados. Mas seria afoito afirmar já terem esses países vencido a batalha da industrialização. Os anos 90 abrem-se como nova etapa crítica, repleta de ameaças e de oportunidades. Sério esforço adicional ainda terá de ser feito por ambos os países asiáticos para chegarem à industrialização, pois, na verdade, quanto mais se aproximam desse nível candidatos ao clube dos industrializados, maiores se tornam os embaraços intencionalmente levantados contra eles.

Quais possibilidades têm Taiwan e Coréia do Sul de efetivarem a ascensão final?

Cumpre começar chamando a atenção para a vaga de fundo que se espraiou pelo mundo após a decisão do Grupo dos 5 (setembro de 1985) de valorizar administrativamente o iene diante do dólar, na chamada Decisão do Hotel Plaza. Nenhuma região foi mais afetada pela vaga em apreço do que o Leste asiático, sob o impacto da conseqüiente internacionalizaçáo das empresas japonesas. Taiwan e Coréia do Sul viram-se compelidos - com notável sincronismo - a abrir politicamente os seus regimes. Em 1987, foi suspensa a lei marcial que vigorava em Taiwan desde 1949. Na Coréia do Sul, o regime militar - no poder desde 1961 - teve de ceder lugar a um sistema presidencial civil, mesmo com o primeiro presidente ainda sendo um general vestido à paisana.

A democratização em marcha nos dois NPIs asiáticos está intimamente ligada à consolidaçáo, em cada um deles, de modernas classes médias urbanas, educadas e exigentes, com forte propensáo consumidora. A demanda doméstica tem compensado em boa medida as dificuldades surgidas no tocante às exportaçóes, $\mathrm{e}$ a ascensáo da classe média vem colocando os dois governos, entre outras coisas, na contingência de encetar custosos programas de melhoria da qualidade de vida, inclusive no combate à poluição ambiental que marchara braço a braço com o desordenado crescimento industrial das décadas anteriores.

Em que pese o sincronismo dessas transformaçóes, vêm elas se manifestando na prática de forma bem diversificada, em consonância com as características socioeconômicas de cada país. Na Coréia do Sul, 
agravaram-se as desigualdades sociais e intensificaram-se os conflitos trabalhistas, logrando os operários industriais dobrar os seus salários entre 1987 e 1992. Uma surda luta vem-se desenvolvendo entre o governo e os poderosos chaebols, à medida em que procuram os últimos liberar-se da mão orientadora do Estado e em que cuida este de coibir a tendência recente dos conglomerados a desviar recursos das obras de construçăo nacional, para operações de tipo especulativo.

Em Taiwan tudo se passa de maneira mais ponderada, sem grande impacto sobre a conhecida condiçáo de uma das sociedades mais equiitativas do mundo. Em 1980, a renda dos 20 por cento de taiwaneses mais ricos era 4,17 vezes mais alta do que a renda dos 20 por cento mais pobres. No final da década, a disparidade tinha crescido para 4,85 vezes mais. Mesmo assim, na segunda metade dos anos 80, Taiwan passou a distinguir-se como país de grande mobilização popular. Sucedem-se as manifestaçóes de todo tipo, em grande parte orientadas para a busca de correção dos problemas de meio ambiente. Digno de nota é o papel assumido pelos intelectuais, em geral organizados em associaçóes específicas, tanto na articulação dos interesses dos cidadáos comuns quanto na atuaçáo como mediadores dos conflitos sociais.

Vem aqui a propósito registrar um desenvolvimento típico de Taiwan. Ao longo dos anos 80, o governo implementou um programa de elevação do nível educacional dos servidores públicos e de aperfeiçoamento do preparo técnico dos mesmos para suas tarefas específicas. Em 1990, cerca de 70\% dos 536 mil funcionários públicos de Taiwan estavam matriculados em colégios ou universidades. Aproximadamente 1000 funcionários tinham sido enviados, no correr da década, para aprimorarem suas educaçóes no exterior. O nível educacional tornou-se o principal parâmetro para a progressáo funcional, e o governo intensificou as políticas de estímulo a taiawaneses emigrados, e detentores de doutorados por universidades americanas, a que viessem integrar-se ao serviço público de Taiwan.

Foi esse corpo de administradores altamente qualificados que claborou e vai acompanhar a implementação do Plano de Seis Anos, concentrado em dez indristrias emergentes: telecomunicaçóes, informação, eletrônica de consumo, semicondutores, maquinaria de precisão $e$ automação, aeroespacial, materiais avançados, química fina e farmacêutica, cuidados médicos e sanitários, controle da poluiçáo. O plano governamental, já aprovado pelo Parlamento, está orçado em 303 bilhóes de dólares, a serem postos basicamente pelos setores público e privado locais, e se tudo der certo fará de Taiwan, no final do século, um dos $\mathbf{3 0}$ países de mais alto padráo de vida do mundo. Oito tecnologias-chaves 


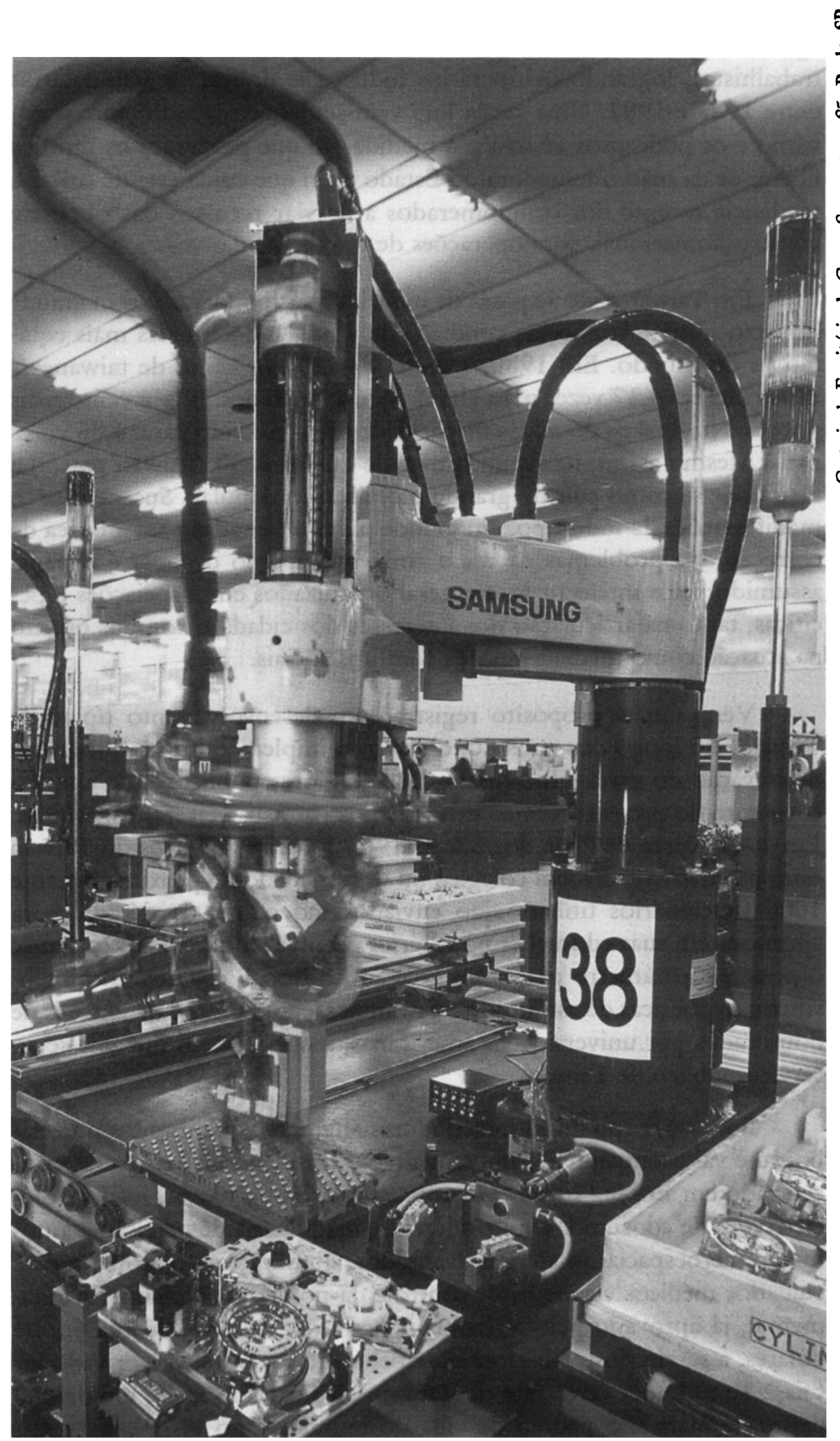

Grupo Samsung: precisáo tecnológica na montagem manual de relógios (à direita) ou na fabricação de cabeças de video cassetes por robôs (à esquerda) 
receberão atenção especial no processo; optoeletrônica, logicial, automaçáo industrial, materiais aplicados, sensores, biotecnologia, desenvolvimento de recursos naturais, conservação de energia.

As importantes industrializações tardias do final do século XIX (EUA, Alemanha e Japão) foram parte integrante da I para a II Revolução Industrial. Também agora, é mister julgar os esforços de industrialização dos NPIs asiáticos em função dos seus entrosamentos com a transiçăo para a III Revolução Industrial. Vale dizer, tendo em conta situações novas como a da chamada globalização econômica. Os critérios do êxito de uma industrializaçáo tardia, na abertura do século XXI, já não são os tradicionais.

O Leste asiático é um dos principais teatros do nascimento da III Revolução Industrial, e Coréia do Sul e Taiwan estão nele imersos, em pelo menos três processos fundamentais: a internacionalização das firmas japonesas; a integração dịnâmica do universo chinês; e a estruturação do Leste asiático como um dos pilares da nascente sociedade da informação.

Na primeira metade dos anos 80 esteve muito em moda a idéia da revoada dos gansos. Promovida pelos japoneses, descrevia essa metáfora um encadeamento dinâmico em que o ganso chefe, o Japão, puxava tecnologicamente os NPIs da orla asiática do Pacífico, os quais, por sua vez, puxavam os países mais atrasados da ANSEA. A visão de que uma

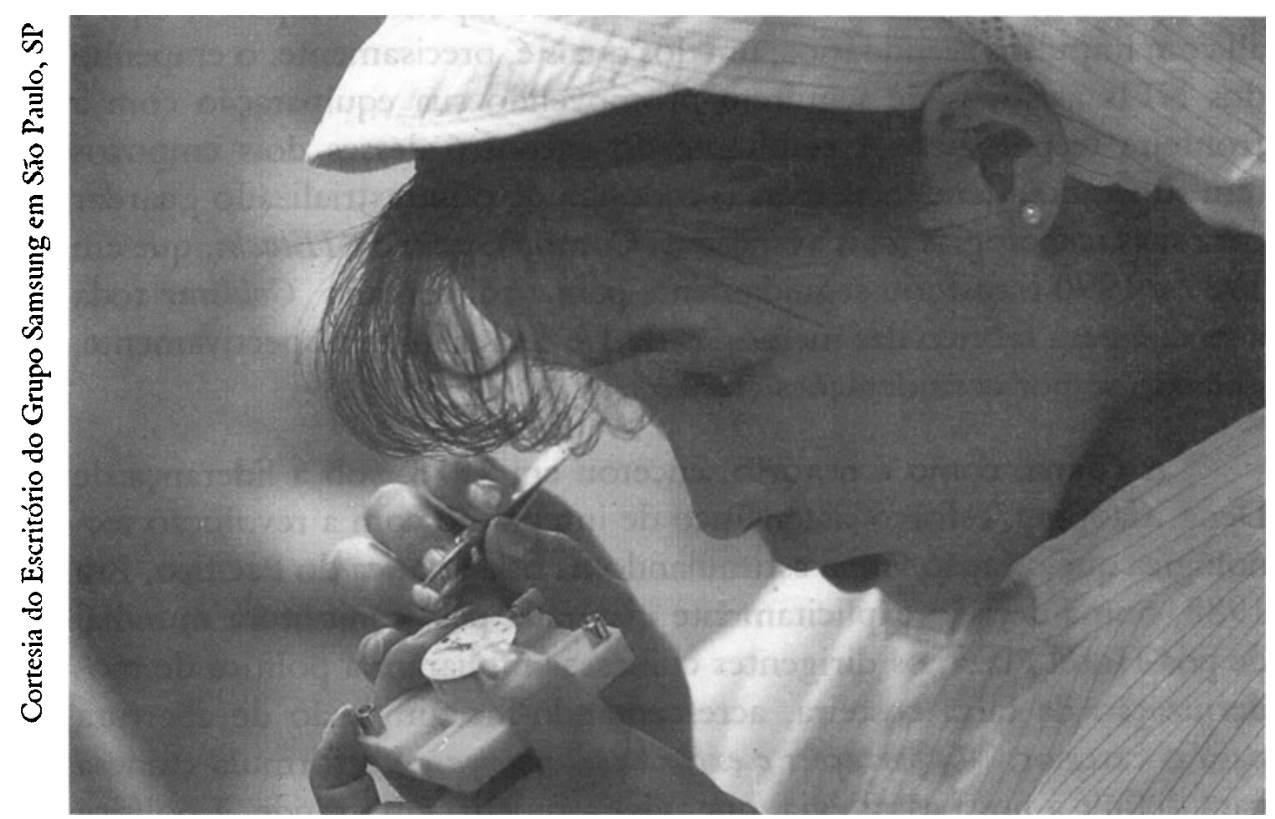


enfiada de gansos a encetarem tranqüilamente seus vôos começou a ser tumultuada, quando os reformistas de Pequim decidiram introduzir no quadro o seu gigantesco dragáo, voando em paralelo e ávido de conectar-se com todos os segmentos de gansos. A situaçăo complicou-se ainda mais depois da Decisão do Hotel Plaza. Os NPIs asiáticos tiveram suas moedas favorecidas pelo jogo cambial dos industrializados, $\mathrm{e} o$ objetivo principal desse jogo (o equilíbrio da balança comercial EUA-Japăo) começou a ser frustrado. A velha complementaridade vertical dos gansos em revoada foi sendo substituída por fortes laços de complementaridade horizontal: entre os NPIs; entre eles e os países da ANSEA; no quadro destes últimos; e entre todos e a China.

A primeira reaçăo das firmas japonesas à Decisão do Hotel Plaza fora intensificar, na segunda metade dos anos 80, a transferência de produção para o exterior, com ênfase em EUA e Europa. As alteraçóes surgidas no Leste asiático logo obrigariam o Japão a rever esta última tendência, incrementando os investimentos diretos nos NPIs asiáticos. É possível explicar, inclusive, a pressa com que o Japão rompeu as fileiras dos industrializados, abandonando a política de sançóes à China de pós-Tiananmen, como tentativa de frear os avanços dos NPIs em direçáo ao mercado chinês, aproveitando o espaço aberto pelas sançóes.

O processo central da globalizafăo vai sendo caracterizado como a decisão estratégica das grandes empresas japonesas de utilizarem, concatenadamente, seus amplos recursos de conhecimento técnico e de capacidade gerencial, na captação de ampla gama de oportunidades comerciais surgidas mundo afora. Esse impulso japonês compóe-se aqui e ali com impulsos secundários, um dos quais é, precisamente, o empenho dos NPIs asiáticos de seguirem promovendo sua equiparação com a fronteira tecnológica. A resultante do encontro desses dois empuxos tem superado a tendência mais comezinha de o industrializado guardar para si as tecnologias mais avançadas. Como no caso da Hitachi, que em 1989 e 1990 transferiu seguidamente para a sul-coreana Goldstar toda a receita para fabrico das memórias de 1 e 4 megabits, respectivamente, guiando-se por consideraçóes comerciais.

A China, como é notório, encetou em 1978, sob a liderança de Deng Xiaoping, esforço sistemático de integração com a revoluçăo tecnológica que o Japáo vinha estimulando na orla asiática do Pacífico. Em 1988, numa decisão explicitamente inspirada pela conjuntura mundial de pós-Hotel Plaza, os dirigentes chineses ampliaram a política de modernizaçáo da faixa costeira, acrescentando-lhe dimensáo de abertura para o exterior. Importafóes exportafóes macifas é a fórmula chinesa para definir a nova estratégia, que, visa a repetir, em grande, a política 
de desenvolvimento puxado pelas exportaçóes, utilizada pelos NPIs nos anos 60. A idéia é depender do exterior tanto para a aquisiçáo dos insumos quanto para o escoamento de manufaturas a serem produzidas em massa nos bolsóes de mão-de-obra barata existentes ao longo da costa do país. Providências estão previstas, evidentemente, para não deixar eternizar-se essa vantagem comparativa elementar. $\mathrm{Na}$ segunda metade dos anos 90 - espera-se - começará a declinar a proporção de mercadorias intensivas em trabalho e a crescer a exportação de mercadorias intensivas em capital e tecnologia. $O$ esquema irá sendo ampliado, de maneira a conectar toda a economia chinesa com o mercado internacional.

A China tem potencial para transformar-se em participante de monta do comércio internacional e, na realidade, já está conquistando substanciais parcelas dos mercados de tecidos, vestuário e calçados, com grande impacto sobre Taiwan e Coréia do Sul. A indústria de calçados de Taiwan praticamente acabou, e outras do mesmo nível tecnológico estáo ameaçadas de igual destino. Diferentemente da Coréia do Sul, onde igual devastação está ocorrendo, pequenos e médios fabricantes taiwaneses, na maior parte dos casos estăo transferindo suas produções para o continente. $O$ esvaziamento de setores inteiros da indústria da ilha preocupa os governantes, que vêem no fato um acicate a mais para o incentivo a indústrias de maior conteúdo científico e tecnológico. Conforme revela a orientaçáo do Plano de Seis Anos para as citadas oito tecnologias-chapes.

No tocante à Coréia do Sul, inexistindo o interdito político que tolhe relaçóes econômicas intensas e transparentes com Taiwan, vem a China desenvolvendo estreita cooperaçáo, já consolidada pelo estabelecimento de relaçóes diplomáticas. O Sexto Plano de Desenvolvimento Econômico e Social da Coréia do Sul (1987-91) determinou a expansão e aperfeiçoamento da estrutura de estradas e portos na costa ocidental do país, precisamente para intensificar o intercâmbio comercial com a província de Shantung, na margem oposta do Mar Amarelo. As possibilidades para um relacionamento mutuamente vantajoso entre os dois países sáo imensas. David Dollar, economista do Banco Mundial especializado no Nordeste asiático, tem chamado a atençáo para a dinâmica complementaridade atualmente existente entre China e Coréia do Sul, tendo em vista seus respectivos estágios de desenvolvimento tecnológico. As manufaturas leves, para as quais a China vem se voltando, são aquelas em que a Coréia do Sul está perdendo competitividade, depois de as ter explorado durante mais de duas décadas. As firmas sul-coreanas desses setores detêm, no entanto, considerável experiência técnica e gerencial que, transferida para a China através de empresas mistas, não 
somente prolongará por algum tempo a vida de empresas sul-coreanas, como propiciará também, para o lado chinês, contribuiçáo em termos de treinamento de mão-de-obra, entre outras, impossível de ser repetida pelas grandes firmas transnaçionais. A experiência chinesa com as implantaçóes de grande tecnicidade dessas empresas tem deixado bastante a desejar. No sentido oposto, agradará certamente aos setores mais modernos da indústria sul-coreana que seu país passe a importar da China as relegadas manufaturas leves, pois isso gerará ganhos no país vizinho, nele criando mercado para os produtos mais elaborados da Coréia do Sul.

Resta considerar o impacto da revolução da informação sobre as industrializaçóes tardias do Leste asiático. O fato central, nesse caso, é a consolidação daquela área como um dos principais pilares da eletrônica mundial, em particular no tocante aos semicondutores. No que tange a estes últimos, $50 \%$ do mercado global concentram-se hoje no Leste asiático, incluindo o Japáo. A parcela dos EUA segue declinando, tendo sido de apenas 27\% em 1991. De acordo com a Dataquest, o Leste asiático (excluído o Japão) deverá ter suplantado a Europa, nas compras de semicondutores, no $4^{\circ}$ trimestre de 1992 . Situaçáo que explica porque firmas como a Texas Instruments ou a Motorola estáo transferindo dos EUA para o Leste asiático parcela crescente das suas operaçóes, inclusive nas fases tecnologicamente mais exigentes.

Nesse contexto, embora ainda sem base científica e poder financeiro que os habilitem a situarem-se entre os líderes, Coréia do Sul e Taiwan já adquiriram boa autonomia de vôo na microeletrônica. Dependem muito de componentes e instrumental do Japáo e dos EUA, mas vão podendo acompanhar a elevaçáo do nível tecnológico e começam a ser buscados por transnacionais desejosas de reforços de capitais (que Taiwan possui em abundância) ou de sangue novo, nos confrontos com companhias concorrentes. Já citamos o caso da Hitachi com a Goldstar. Em dezembro de 1992, foi a Toshiba que se aliou com a sul-coreana Samsung, a fim de promover sua versão das supermemórias ditas flashes. Pouco antes, a TI associou-se à taiwanesa Acer para criar moderníssima fábrica de memórias no Parque de Ciência de Hsinchu. A firma taiwanesa entrou com $\mathbf{7 4 8}$ dos 300 milhóes de dólares que custará a fábrica.

Em suma, se ainda não é possível afirmar que Coréia do Sul e Taiwan venceram a batalha da industrializaçáo, tampouco é lícito dizer que os dois países estão atingindo os limites de suas caminhadas. Toda a fronteira tecnológica atravessa fase de grande fluidez, na qual a flexibilidade e rapidez das reaçóes às inconsistências do mercado mostram-se 
por vezes mais importantes do que a enormidade de recursos associada a estruturas mais rígidas. Abundam os exemplos em que os NPIs asiáticos têm suprido com engenho e arte, usando conhecimentos já disponíveis, sua incapacidade material de lançar-se a exigentes programas de pesquisa e desenvolvimento.

\title{
Resumo
}

A economia mundial está atravessando uma das fases críticas que - na Idade Industrial - têm-se alternado com períodos de estabilidade hegemônica. Os dois séculos já decorridos desde a Revolução Industrial (Inglaterra, final do século XVIII) mostram que é nas fases de ruptura das estabilidades hegemônicas que sociedades dinâmicas conseguem realizar a façanha da sua própria industrialização. Taiwan e Coréia do Sul cstão procurando fazer isso, precisamente. Estabelecida essa premissa, o artigo dedica-se entāo a examinar de forma abrangente a maneira como as duas economias do Leste Asiático vêm podendo levar adiante as respectivas industrializações tardias.

\begin{abstract}
Word economy is going through one of those phases of general disruption and restructuring that, in the course of the Industrial Age, have typically alternated with periods of the Industrial Age, have typically alternated with periods of hegemonic stability. The two centuries already passed since England pioneered Industrial Revolution, show us that those phases of restructuring are very important for dynamic societies intended in implementing their own late industrialization. At the present time, Taiwan and South Korea are trying to do this, precisely.

After establishing this premise, the article goes on with a comprehensive presentation of how the two East Asian economies are going forward with their plans.
\end{abstract}

Amaury Porto de Oliveira, diplomáta de carreira, foi embaixador do Brasil em Cingapura e professor visitante da Área de Assuntos Internacionais do Instituto de Estudos Avançados (IEA) da USP entre 1991 e 1992 . É autor de "Cartas de Cingapura". 